\title{
Study on RFID-based Automobile Parts Enterprises Warehouse Management System
}

\author{
Huang Feng \\ Huazhong University of Science and Technology \\ Liuzhou Railway Vocational Technical College \\ 18907721995@189.CN
}

\author{
Wang Daxi, Wu Jun, Lei Xiaorong \\ Guangxi University of Technology \\ wangdaxi8@126.com,Wujunhf1@163.com \\ Cao Hanqiang \\ Huazhong University of Science and Technology
}

\begin{abstract}
Radio frequency technology is a new identification technology, which developed relatively fast in recent years, and its superior performance with high value, this article combination of warehouse management of automobile parts industry, analysis of radio frequency technology in the warehouse management application. Traditional marketing is undergoing a fundamental change, global supply chain management concept has also been growing recognition. With the continuous development of supply chain management, warehousing has become an important link of supply chain management . In order to reduce inventory and improve order fulfillment rate, companies must pay attention to the use of various resources and use of space in order to optimize inventory and improve efficiency. In this article, combination with RFID, for warehouse storage proposed a management system program to improve efficiency, enhance the competitiveness of enterprises.
\end{abstract}

\section{Keywords-Identification technology, RFID, Management}

\section{OVERVIEW OF RADIO FREQUENCY TECHNOLOGY}

Traditional marketing is undergoing a fundamental change, global supply chain management concept has also been growing recognition. With the continuous development of supply chain management, warehousing has become an important link of supply chain management . In order to reduce inventory and improve order fulfillment rate, companies must pay attention to the use of various resources and use of space in order to optimize inventory and improve efficiency. In this article, combination with RFID, for warehouse storage proposed a management system program to improve efficiency, enhance the competitiveness of enterprises.

Radio frequency using Wireless radio frequency between reader and Radio frequency cards in non-contact two-way data transmission, to achieve the target identification and data exchange purposes. Compared with the traditional bar code, magnetic card and IC card, radio frequency card provided with features of non-contact, reading speed quickly, no wear, not environmental impact, long life, easy to use and have anti-collision function, can deal with multiple cards. In other countries, radio frequency identification technology has been widely used in industrial automation, business automation, transportation control and management and other fields.

\section{RADIO FREQUENCY SYSTEM WORK FLOW}

Reader through the transmitting antenna to send a certain frequency of radio signals, when the radio frequency card enter into the transmitting antenna work area induced electric current, Radio frequency card is activated access of energy ;Radio frequency card send its own encoded and other information by its own built-in transmitting antenna to send out; system receives Antenna receive the carrier signal sent from the radio frequency carrier, transmitted by the antenna controller to the reader, readers deal with the received signal demodulation and decoding and then sent to the background related to the main system for processing; the main system under the logical operations to determine the card Legitimacy, and make the appropriate settings for different treatment and control, issue command signals control of the implementing agencies action. Specifically shown in Figure 1:

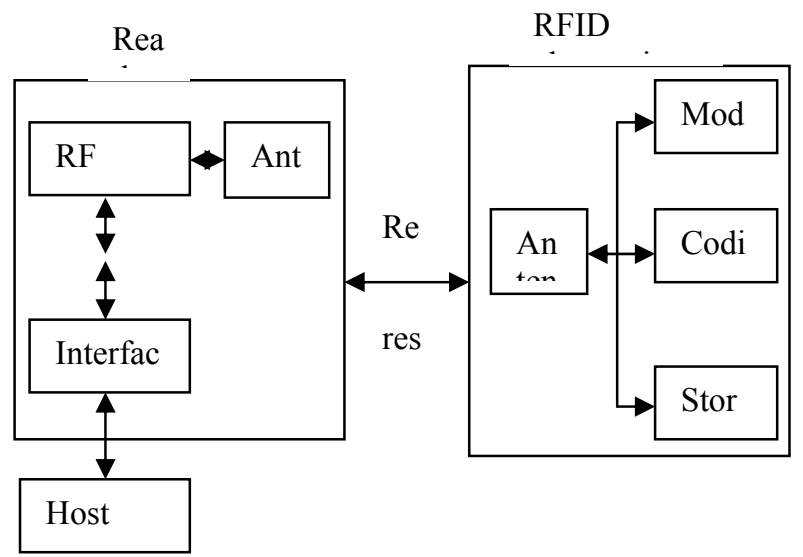

Figure 1. System block diagram

\section{APPLICATION IN THE WAREHOUSE MANAGEMENT}

\section{A. Electronic tag}

In the production process, the label can be divided into two categories: raw materials label and finished goods label. 
Figure 1 can learn from the label structure, the main raw material information is put the basic information of materials by reading devices in the memory, when the electronic tag into the reader formed the magnetic field, when received the radio frequency transmitter Signal from the reader, induced current, with energy the label is activated. Modulator deal with the emitted from reader radio frequency signal read out the corresponding command, Sent the necessary data of the reader from the transceiver module. The same principle, for the product code is the same steps. Read the work of the process is as follows:

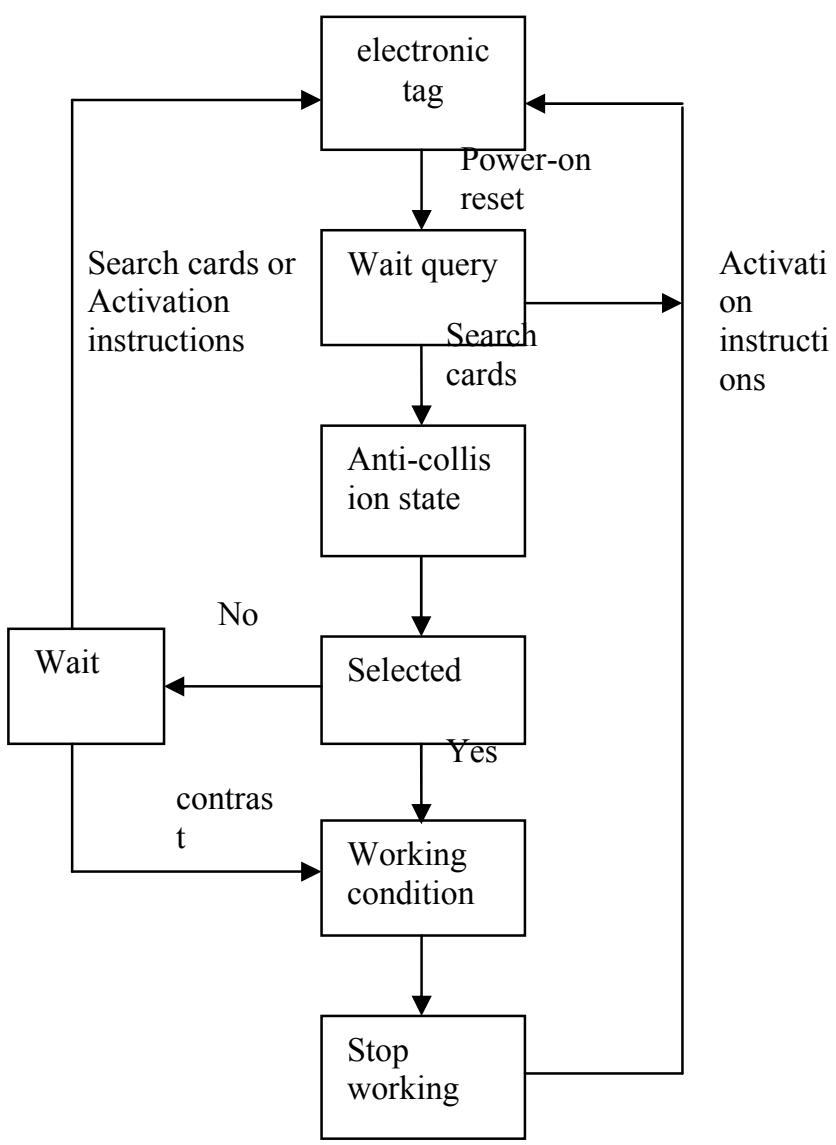

Figure 2. electronic tag workflow

Coding for the electronic tags can be applied EPC, encoding. EPC code has 64-bit, 96-bit and 256-bit 3, all by the numbers. For example, in the following two electronic tags used codes for the EPC-64 II type and EPC-96 code:

100000000000001110000000000111000000000000000 000000000000000011101 • 0000A89 • 00016F • 000169DC0 encoding (ABCDEF) is 10-15 in hexadecimal numbers. The code contains the product number. Production or service enterprises, object classification (product), the serial number and other information.

\section{B. Storage management}

Storage management is divided into two parts: storage of raw materials and finished products storage. Then the raw material storage, follow these steps:

When the Treasury put forward the demand supplier, the supplier required to generate and print and paste bar code of raw materials, the distribution of raw materials after delivery to the specified raw materials warehouse, quality inspection by the quality inspection department, After inspection put purchase of raw materials to storage scan. Routing tag via remote transmission of information system, updated inventory information. Batch scanning can be carried out to improve efficiency.

Throughout the assembly process is completed the finished product storage; generate product labels. In which the input tag information includes drawing number information of the product, date of production information, assembly line information, frequency information, pattern information, generate number, inspectors information and so on. After the bar code paste to the products can do off the assembly line scan, a scan gun login information with the tag line frequency and assembly line information. The following is the finished product storage workflow:

\section{Out of Warehouse management}

Out of Warehouse also divided into two parts: raw materials and finished products.

1) raw materials out of Warehouse

Picking in the production process to manage with the use of electronic tags, packaging suppliers to try picking picking required by the production department for packaging, therefore when the production sector received material ,no need for raw materials for re-packing and adhesive labels. At the same time large quantities of picking process, through high-speed read the information on the label, reducing picking time. When production is completed, the warehouse keeper of the production expected to receive the audit, audit documentation after the collar material generated by the system and print, Production departments and the Treasury expected to receive data on the production of picking the data to confirm and completion of the transition picking, Production picking operation flow is as follows: 


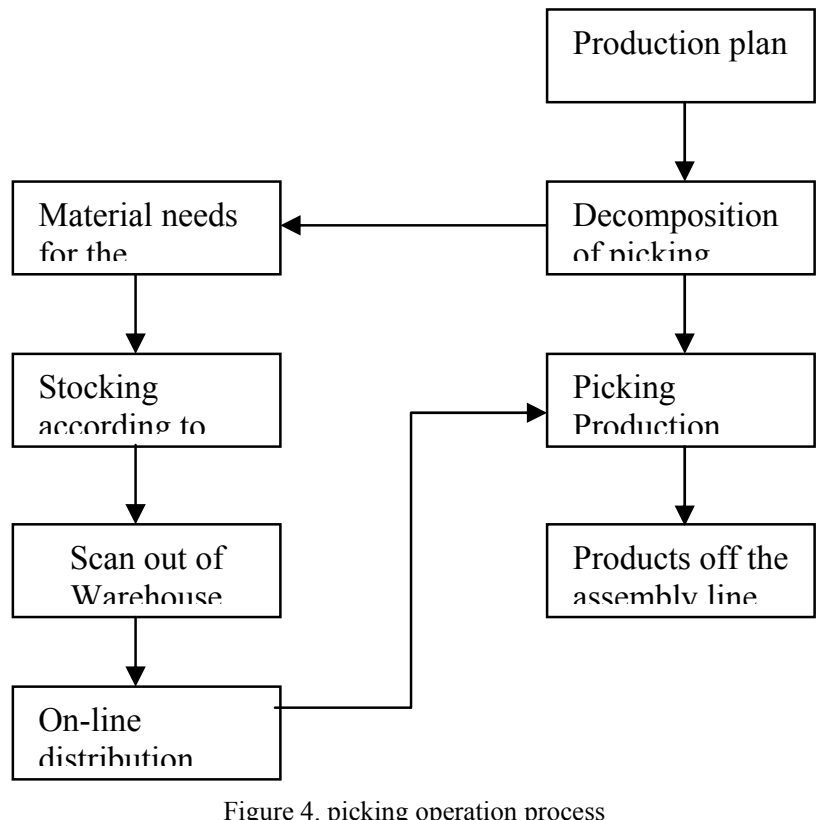

2) finished products out of Warehouse

(1) the goods before out of Warehouse:

Use of RFID system, RFID system operators through the certificate out of Warehouse to input the information, the system queries the certificate out of Warehouse to comply with the goods, meet the requirements generate selection list, including requisition number, position selection, code, box number, destination, the whole package number, position the selection in accordance with the instructions pre-set rules for automatically generating a graphical interface prompts, allowing the operator to manually specified in the system.

(2) The selection out of Warehouse:

Selection out of Warehouse steps, you can refer to the process of RFID system, to be worthy of note here is: different goods may be individually packaged, may also be classified according to product packaging, or a few products of a plate. The former does not require unpacking or sorting, can be shipped directly out of Warehouse; the last two cases will split of zero and sorting out the Warehouse after the delivery. Split of zero and sorting can not be completely to avoid, which requires effective control of RFID system to split of zero, and sorting the various split zero unit of the flow and other information (including the authorized officer, operator, time, reason, etc.).

(3) recognized out of Warehouse:

Delivery of transport vehicles to the Warehouse, the operating personnel out of Warehouse checks to determine the selection and requisition of goods or the delivery notice is consistent, complete validation out of Warehouse; where requests the final goods will need to synchronize out of Warehouse information to the WCS system, And in the SCM system to complete out of Warehouse recognized and print out of Warehouse list.

\section{ACKNOWLEDGE}

This article has achieved of Guangxi Science and Technology Project: Intelligent bar-code technology on the automotive components business of Logistics Information System (Guangxi Science and Industry 0815003-1)-funded

\section{CONCLUSION}

Combined with RFID technology, warehouse management system helps managers to enter Warehouse, out of Warehouse, transfer Warehouse, inventory, supplementary of ordering and production of feeding and other operations to conduct a comprehensive control and management. The enterprise storage management of this very important and critical part to better help companies benign operation.

\section{REFERENCES}

[1] An end of bar code of new technologies-RFID in Warehouse field [J] Warehouse Science, 2004 (9) :9-11

[2] Li Jintao, Guo Junbo, Luo Haiyong, etal. Radio Frequency Identification (RFID) technology and its application [J]. Information Technology Letters, 2004 (11) :1-10

[3] Zheng Pingbiao, Hou Hai, Yong Fan,etal. Technology in warehouse management system, railway freight, 2005 (12) :18-21

[4] Pang Juan, Warehouse management system integration [J]. China Transportation, 2004 (5) :47-48

[5] Geng Xuefei, RFID Technology in Logistics Management [J].Packaging Engineering, 2005 (6) :118-119

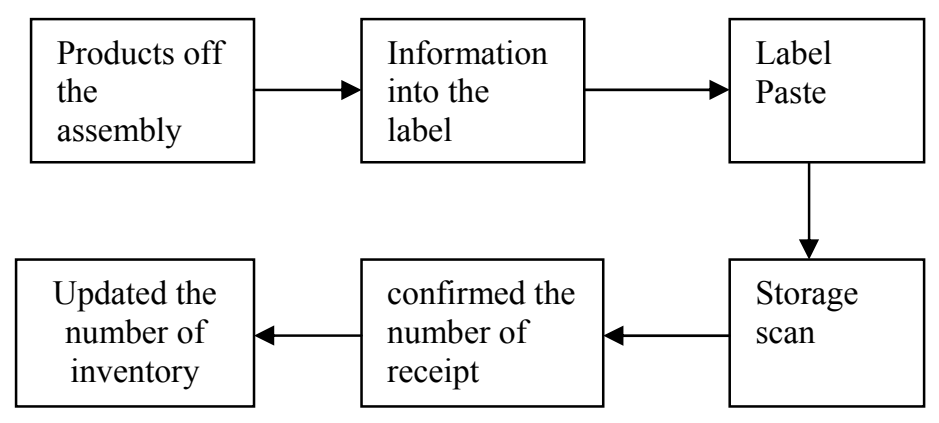

Figure 3. Chart of product storage workflow 